\title{
NUMERICAL AND EXPERIMENTAL ANAL YSIS OF THE FLOW OVER A COMMERCIAL VEHICLE - PICKUP
}

\begin{abstract}
W. J. G. S. Pinto,
and $\mathrm{O}$. Almei da

Centro dePesquisa em Aerodinâmica

Experimental - CPAERO

Faculdade de Engenharia Mecânica

Av. João Naves de Ávila, 2121

Campus Santa Mônica

CP. 38408, Uberlândia, Minas Gerais, Brazil odenir.almeida@ufu.br wagnerjgsp@hotmail.com

Received: July 30, 2018

Revised: September 20, 2018

Accepted: October 30, 2018

ABSTRACT

This work presents an ongoing numerical and experimental study of the flow around a pickup vehicle by means of CFD simulations and wind tunnel experiments. The model was based on the light-pickup market in Brazil and it was designed with flat surfaces and sharp edges. One of the objectives of this research was the understanding about the flow pattern around the vehicle, especially in the region behind the cabin and the wake. Another goal was to obtain original data from experimental measurements which could be used on further computational investigations. The experiments were carried out in a low-speed wind tunnel at Reynolds number of $5 \times 10^{5}$. Hot-wire anemometry was used to obtain the velocity profiles. Wall tufts were applied to describe the flow direction and regions of attached/detached and recirculation zones. Acceleration due to the underbody and the shear layer formed on the cabin were well defined, also indicating a region of reverse flow behind the tailgate. The flow visualization allowed the identification of recirculation regions inside the trunk and regions of detached flow. These flow patterns were also reproduced in the CFD simulations resulting satisfactory information to describe the main flow pattern over the pickup vehicle.

Keywords: aerody namics; pickup; tailgate; hot-wire anemo metry; CFD
\end{abstract}

\section{NOMENCLATURE}

$\mathrm{U}$ uniform flow velocity, $\mathrm{m} / \mathrm{s}$

$\mathrm{Y}_{+} \quad$ dimensionless wall distance

I turbulent intensity, \%

$\mathrm{k}$ turbulent kinetic energy, $\mathrm{m}^{2} / \mathrm{s}^{2}$

$\mathrm{L} \quad$ pickup length, $\mathrm{m}$

1 pickup bed length, $m$

$P \quad$ pressure, $\mathrm{N} / \mathrm{m}^{2}$

$\mathrm{P}_{1} \quad$ position 1 - upstream, $\mathrm{mm}$

$\mathrm{P}_{2} \quad$ position 2 - downstream, $\mathrm{mm}$

$\mathrm{P}_{3} \quad$ position 3 - downstream, $\mathrm{mm}$

$\mathrm{C}_{\mathrm{p}} \quad$ pressure coefficient

$\mathrm{Re}_{\mathrm{L}} \quad$ Reynolds number based on pickup length

St Strouhal number

$\mathrm{T}$ acquisition time, $\mathrm{s}$

$\mathrm{H}$ shape factor

$\mathrm{x}, \mathrm{y}, \mathrm{z}$ cartesian coordinates, $\mathrm{m}$

\section{Greek symbols}

$\beta \quad$ blockage ratio, $\%$

$\delta \quad$ layer thickness, $\mathrm{mm}$

$\theta$ displacement thickness, $\mathrm{mm}$

$\omega \quad$ dissipation rate, $1 / \mathrm{s}$

$v \quad$ fluid kine matic $v$ iscosity, $\mathrm{m}^{2} / \mathrm{s}$

$\rho$ density, $\mathrm{kg} / \mathrm{m}^{3}$

\section{Subscripts}

$0 \quad$ undisturbed flow RMS root mean square turb turbulent

max maximum

\section{INTRODUCTION}

The knowledge of the flow pattern over a commercial vehicle such as pickups is very important in the modern automotive industry. As pointed by Almeida et al. (2017), the presence of an open trunk is responsible for a unique flow topology within a natural great interest for manufacture's research. Also, academic works are being developed at this time. In fact, the improvement in the aerodynamic performance of pickup trucks is very important in the present market especially because these vehicles have drag coefficients higher than other ones, such as passenger car or sports utility vehicles (SUVs). Therefore, the study of the aerodynamic of pickups plays a role in fuel consumption because any improvement in drag reduction means fuel efficiency saving lots of money in the current global market.

A notable example of initiatives for researching in this specific area of commercial vehicles is the Brazilian INOVAR-AUTO program (http://www.inovarauto.md ic.gov.br/InovarAuto/publ ic/inovar.jspx?_adf.cirl-state-6nan5b3fo_9< <accessed in $05 / 04 / 2015>$ ), which intends to promote $R \& D$ investments for companies that produce, distribute or present projects to invest in the automotive production in Brazil - Almeida et al. (2017). One of its pillars is reducing fuel consumption, for instance, a decrease of $18.84 \%$ by 2017 will result in $2 \%$ direct 
tax reduction for the final product. In this context, it is known that the mix of passengers and cargo fills a specific demand but remains representative in the automotive market. In 2014, according to FENABRA VE (National Federation for Vehicle Distribution) they comprehend $83.11 \%$ of the licensing for the light commercial sub segment (composed by pickups and vans) what represented $12.68 \%$ of total Brazilian automotive market (including car, trucks and buses) (http://www3.fenabrave.org.br:8092/plus/modulos/co nteudo/?tac $=$ dados-regionais - dados <accessed in 05/04/2015>). In November 2015, pickups represented $9 \%$ of auto sales in United States according to the Wall Street Journal (http://online.wsj.com/mdc/public/page/2_3022-

autosales.html <accessed in 05/04/2015>). Although the analysis of the external flow around pickups is mostly restrict to the manufactures, it attracts academic work due to its complex tridimensional flow, even serving as test case for numerical algorithms under development. Experimental and numerical works discuss the subject, focused mostly in flow description and drag estimation/reduction techniques.

A closely view in the literature points out to previous numerical and experimental studies on simplified geometries and some like to the market pickup trucks models, according to the works of AlGarni et al. (2003), Cooper (2004), AgelinChaab (2014) among others. However, it is important to observe that the amount of data and geometry available is still very restricted and impose some difficulties to enhance the knowledge about the subject. A major contribution to the academic study of pickup's aerodynamic was made by AlGarni (2003, 2008) and Al-Garni and Bernal (2010) for a generic model, scale $1 / 12$, where PIV and pressure measurements were conducted. These works provided information about the geometry and fluid dynamics data giving a better understanding of the flow variation inside the bed and near wake of the tailgate. The proposed geometry and the results of Al-Garni et al. (2003) are recurrent on academic literature, so far. Also, very similar flow topologies were obtained with different geometries, Mokhtar et al. (2009), Ha et al. (2009) as additional examples.

This numerical and experimental study was aimed to the general description of the external flow around a pickup vehicle. A simplified model was built from averaged dimensions of the vehicles with the biggest market share in the Brazilian light pickups market. Two objectives were envisaged in this work being the first one related to a better understanding of the flow pattern around such vehicle and a second goal for providing a new geometry, like commercial pickups, and fluid dynamics data for further investigations by using computational fluid dynamics (CFD). This work is part of an ongoing research on aerodynamic of commercial vehicles such as pickup,
SUV's (Sport Utility Vehic les) and notchbacks, and it has been developed under the INOVAR-AUTO program to improve aerodynamic and consequently reduce fuel consumption.

\section{TES T ARTICLE}

To have a geometry (test-article) that characterizes the most common commercial vehicles in the Brazilian market, a statistical averaged-model was stablished based upon the most typical models in the light pickup market.

As presented by Almeida et al. (2017), 26 external dimensions were obtained from manufacturer's website, customer manuals and from photographs which have been processed to generate the final geometry - Table 1 . A mean error of $4.5 \%$ is observed for all the scale tests. The final model dimensions $(\mathrm{mm})$ are presented in Fig. 2.

\begin{tabular}{|c|c|c|c|c|c|}
\hline POS. & MODEL & JULY & MARKET JULY & JUNE & MARKET JUNE \\
\hline $1^{\circ}$ & Fiat STRADA & 12585 & $56.28 \%$ & 10559 & $53.78 \%$ \\
\hline $2^{\circ}$ & Volkswagen SAVEIRO & 7294 & $32.62 \%$ & 6721 & $34.23 \%$ \\
\hline $3^{\circ}$ & Chevrolet MONTANA & 2446 & $10.94 \%$ & 2319 & $11.81 \%$ \\
\hline $4^{\circ}$ & PEUGEOT HOGGAR & 23 & $0.10 \%$ & 23 & $0.12 \%$ \\
\hline $5^{\circ}$ & HAFEI MINI & 11 & $0.05 \%$ & 13 & $0.07 \%$ \\
\hline \multirow[t]{2}{*}{$6^{\circ}$} & Ford COURIER & 1 & $0.00 \%$ & - & $0.00 \%$ \\
\hline & TOTA & 22360 & $100.00 \%$ & 19635 & $100.00 \%$ \\
\hline
\end{tabular}

Figure1. Brazilian's light pickups licensing in July 2014 (source: Fenabrave) - after Pinto (2016).

Table 1. Statistics of dimension-analysis - Meanmodel.

\begin{tabular}{|c|c|c|c|c|c|}
\hline LABEL & MAXIMUN & MINIMUN & MEAN & $\begin{array}{c}\text { STANDARD } \\
\text { DEVATION }\end{array}$ & $\begin{array}{c}\text { COEF. OF } \\
\text { VARIATION }\end{array}$ \\
\hline A & $1,550.12$ & $1,425.00$ & $1,468.04$ & 71.11 & $4.8 \%$ \\
\hline B & $1,490.71$ & $1,390.00$ & $1,429.09$ & 46.46 & $3.3 \%$ \\
\hline C & $1,094.03$ & 995.32 & $1,056.00$ & 53.11 & $5.0 \%$ \\
\hline D1 & $1,578.00$ & $1,402.43$ & $1,506.29$ & 68.94 & $4.6 \%$ \\
\hline D2 & $1,630.00$ & $1,497.00$ & $1,557.47$ & 58.85 & $3.8 \%$ \\
\hline E & 265.28 & 170.00 & 226.80 & 40.92 & $18.0 \%$ \\
\hline F & 877.18 & 821.21 & 849.84 & 24.59 & $2.9 \%$ \\
\hline G1 & $1,793.00$ & $1,664.00$ & $1,706.60$ & 52.00 & $3.0 \%$ \\
\hline G2 & $2,020.40$ & $1,893.00$ & $1,934.35$ & 58.27 & $3,0 \%$ \\
\hline H & 66.37 & 58.00 & 62.33 & 3.43 & $5.5 \%$ \\
\hline I & 12.80 & 9.04 & 10.76 & 1.49 & $13.9 \%$ \\
\hline J1 & 32.59 & 20.93 & 25.85 & 4.26 & $16.5 \%$ \\
\hline J2 & 27.77 & 21.92 & 25.50 & 2.22 & $8,7 \%$ \\
\hline K & 31.86 & 29.40 & 30.80 & 1.07 & $3.5 \%$ \\
\hline L & 27.51 & 9.87 & 19.25 & 7.65 & $39.7 \%$ \\
\hline M & 844.00 & 680.00 & 770.30 & 61.47 & $8.0 \%$ \\
\hline N & $2,893.42$ & $2,669.00$ & $2,755.08$ & 83.74 & $3.0 \%$ \\
\hline O & $1,001.00$ & 872.09 & 908.34 & 52.82 & $5.8 \%$ \\
\hline P & $4,526.00$ & $4,409.00$ & $4,479.80$ & 47.46 & $1.1 \%$ \\
\hline Q1 & $1,249.25$ & $1,058.72$ & $1,175.27$ & 76.35 & $6.5 \%$ \\
\hline Q2 & 525.00 & 464.00 & 494.50 & 43.13 & $8.7 \%$ \\
\hline R & $1,760.32$ & $1,615.46$ & $1,700.99$ & 55.78 & $3.3 \%$ \\
\hline S & $1,119.00$ & 920.00 & $1,057.25$ & 92.29 & $8.7 \%$ \\
\hline T1 & $1,340.00$ & $1,230.00$ & $1,270.00$ & 60.83 & $4.8 \%$ \\
\hline T2 & $1,350.00$ & $1,350.00$ & $1,350.00$ & - & - \\
\hline V & $1,680.00$ & $1,640.00$ & $1,660.00$ & 28.28 & $1.7 \%$ \\
\hline
\end{tabular}

The model was designed in the software CATIA ${ }^{\circledR}$ V5R20 using the dimensions presented on Table 1 considering the proper tire-dimension for each model. The model was made entirely composed by sharp edges and flat surfaces; the three-views drawing is also presented in Fig.2. The sharp-edge and flat-surfaces model was labeled as "baseline". To comprehend the effects of the sharp edges, a second version of the model ("rounded" version) was prepared by adding a fillet of $15 \mathrm{~mm}$ on all the 
external edges and a fillet of $6 \mathrm{~mm}$ on the exterior of the bed; the bed interior is the same for the baseline model. Both models are also illustrated in Figure 2.

The baseline model to be tested in the wind tunnel was printed in the scale $1 / 10^{\text {th }}$ using a MakerBot 3D® printer with an ABS filament of $1.5 \mathrm{~mm}$ diameter. Additional superficial texture and corrections for some distortions were applied to the models. The finalized model is presented in Fig. 3.
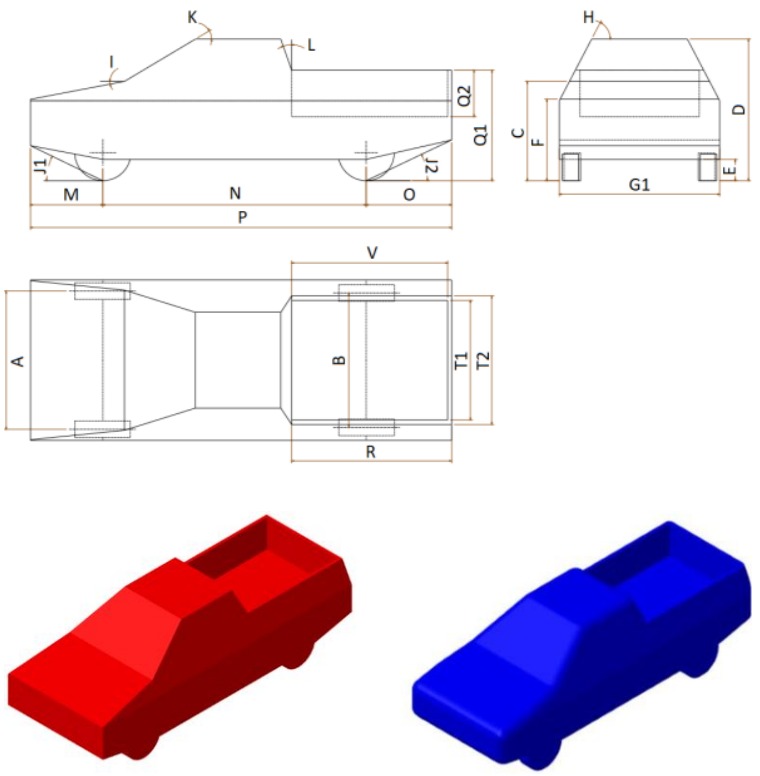

Figure 2. Final pickup-model main dimensions.

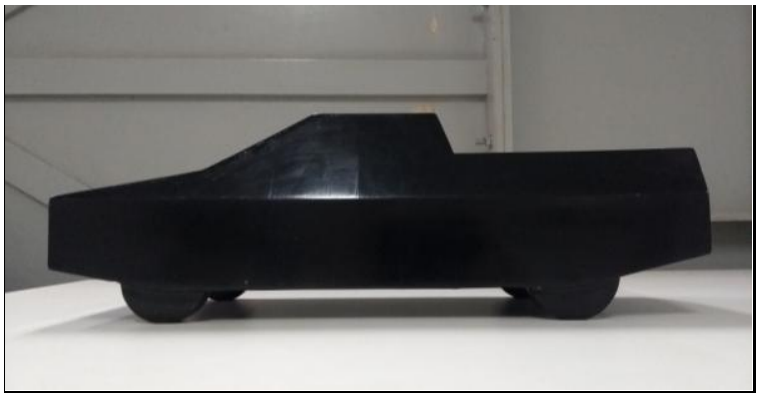

Figure 3. Pickup truck test article $\left(1 / 10^{\text {th }}\right.$ scale).

As this is an ongoing study, in this work only the results for the baseline (pickup with flat surfaces) configuration will be shown. Additional data is being gathered for the pickup with $15 \mathrm{~mm}$ fillet (rounded version) and it will be presented in future publications.

\section{EXPERIMENTAL ARRANGEMENT}

The experiments were carried out in TV-60, a low-speed wind tunnel with cross-sectional area of $60 \times 60 \mathrm{~cm}^{2}$ located at the External Aerodynamics Research Center (CPAERO) from Federal University of Uberlandia, Brazil, as illustrated in Fig. 4. The maximu $m$ air speed in the wind tunnel test section is approximately $30 \mathrm{~m} / \mathrm{s}$ with minimal blockage. As discussed by Almeida et al. (2017), the turbulence intensity at top-speeds is around $0.5-0.8 \%$, providing a good flow quality for aerodynamics analyses in this size of equip ment.

Additional details for the experimental work could be gathered in Almeida et al. (2017). The model was mounted inside the test section with no movable ground. Measurements of the displacement thickness of the ground boundary layer were carried out before proceeding to the tests with the model. The maximum measured displacement thickness on empty test section was around $1 \mathrm{~mm}$, what represents $4.5 \%$ of the ground clearance.

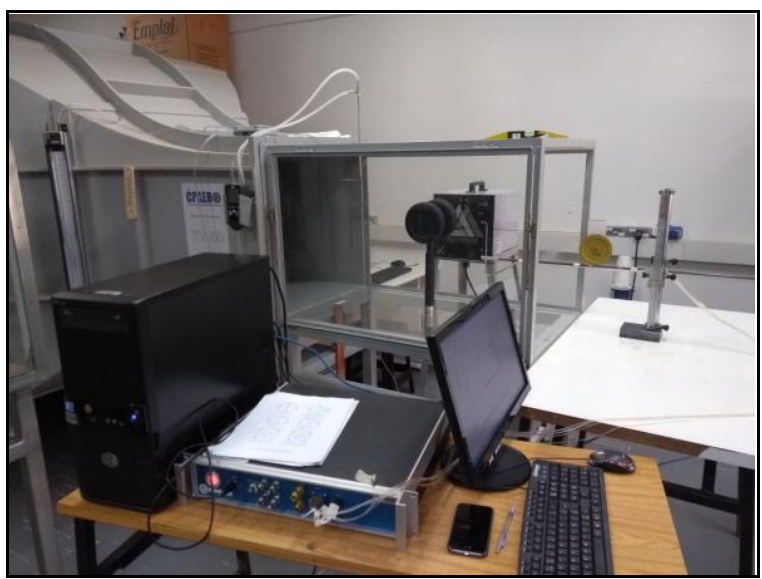

Figure 4. Wind Tunnel test-facility (TV-60 CPAERO).

As described in Almeida et al. (2017), hot-wire anemo metry system was applied to quantify the flow upstream and downstream the vehicle, as illustrated by Fig. 5.

The velocity profile measurements points were placed on three different axes at the symmetry plane of the pickup (see Fig. 5): $78 \mathrm{~mm}$ - bed's length (l) before the model (P1); $50 \mathrm{~mm}$ and $92.57 \mathrm{~mm}-$ approximately tailgate height (h) and its first multiple - after the model (P2 and P3, respectively). As discussed by Almeida et al. (20017), no previous study has helped to select these locations since at the time there was no information about the size of the recirculation zone behind the vehicle.

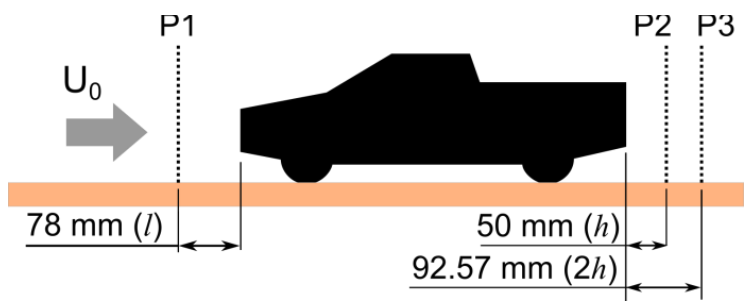

Figure 5. Hot-wire anemo metry acquisition points velocity profiles, after Almeida et al. (2017).

Measurements were performed from the ground 
starting at $5 \mathrm{~mm}$ up to $170 \mathrm{~mm}$, each $5 \mathrm{~mm}$ (total of 34 measurements points per position), being these positions one of the restrictions of the positioning device (traverse system). To complement the flow analysis, wall tufts were applied as flow visualization technique. Wool tufts of $15 \mathrm{~mm}$ long were glued on some parts of the pickup walls as described in Fig. 6.

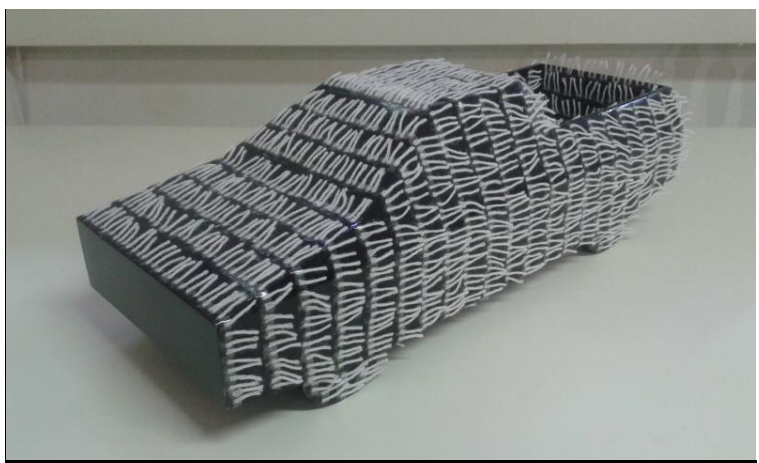

Figure 6. Pickup model with wool tufts.

The tests were recorded with a high definition camera posed on a tripod in front the fiber-glass wind tunnel's window. The effects on the trunk were also registered from the top via a hole on test section roof using an additional camera. Recording were made for two flow velocities investigated: 16.7 and $25.0 \mathrm{~m} / \mathrm{s}$.

\section{NUMERICAL APPROACH}

The three-dimensional (3D) flow field simulation around the pickup model was performed using the steady Reynolds Averaged Navier-Stokes equations (RANS) with the aid of the commercial software STAR-CCM+®. The turbulence model was the SST k- $\omega$, proposed by Menter(1994), with standard coefficients. This model was selected due to its good applicability and results in adverse pressure gradients and separating flow conditions as indicated by HA et al. (2011). Solution was based on the segregated flow model (2nd order upwind convection scheme) with all $\mathrm{y}+$ wall treatment. Fluid was incompressible air (standard properties: $1.18 \mathrm{~kg} / \mathrm{m}^{3}$ density and $1.85 \times 10^{-5}$ Pa.s dynamic viscosity); reference pressure was also let on standard $(\mathrm{P}=101,325 \mathrm{kPa})$. To reproduce the wind tunnel setup, the ground was kept fixed and wheels were with no rotation, both surfaces with non-slip conditions. The far field (both upper field and side field) was defined as walls with slip condition. Inlet flow condition was set with constant velocity (16.67 and $25.00 \mathrm{~m} / \mathrm{s}$ ), turbulent intensity was set to $1 \%$ and the turbulent velocity scale was fixed at $10 \%$ of the free stream velocity. The mesh was created in the software ANSYS ICEM CFD 16.0® and the numerical domain dimensions were based on the vehicle's length L and follow the proportions used by Ha et al. (2011). As summarized on Fig. 7, the in let condition was placed forward the model at $10 \mathrm{~L}$, the outlet was located 20L downstream the model, the superior limit of the domain was at $10 \mathrm{~L}$ of the ground and the lateral limit was placed after $7.5 \mathrm{~L}$ the model. Only half of the model was simulated with $0.06 \%$ blockage ratio.

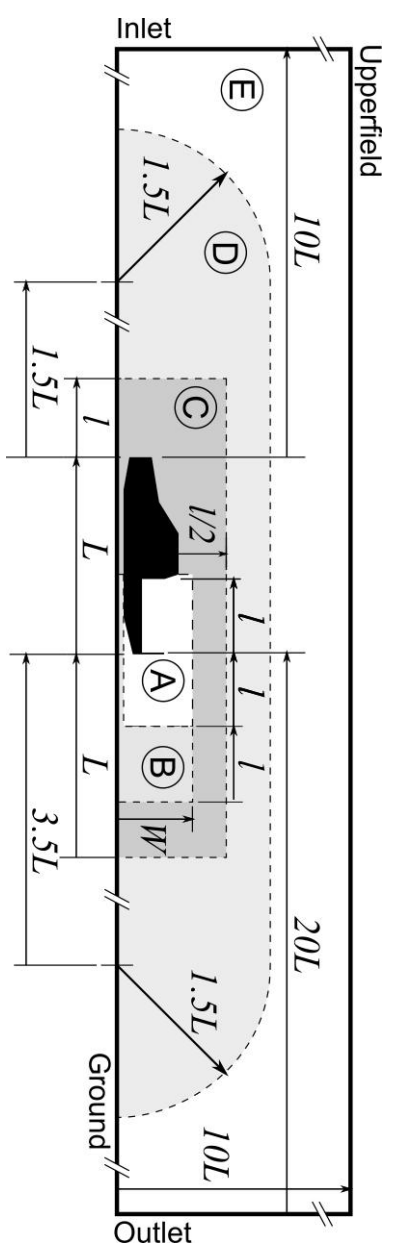

Figure 7. Refine ment regions on symmetry plan ( $\mathrm{L}$ is the pickup length; $\mathrm{I}$ is the trunk length; and $\mathrm{W}$ is the pickup width.

For better accuracy for flow representation, the elements of the mesh were refined in specific regions, especially in the trunk and in the wake. Five volumetric regions, defined by letters (A) to (E) in Fig.7, represents the different mesh refinement applied in this work, according to the following parameters:

- trunk density: element size of $2 \mathrm{~mm}$, corresponds to the trunk and the closer portion of the wake. It starts at the end of the rear surface of the cabin; Labelled as (A) on diagram;

- wake density: element size of $5 \mathrm{~mm}$, comprehends both the later wake and the underbody of the model; (B) on diagram;

- inner density: size of $10 \mathrm{~mm}$, englobes all the pickup and affects both before and after the model; (C) on diagram;

- outer density: size of $40 \mathrm{~mm}$, an expansion of the previous density; (D) on diagram. 
- wheel density: variable size, minimum of 0.5 $\mathrm{mm}$ on the contact with the ground; one for each wheel, not represented in the diagram.

On the rest of the domain - represented as (E) the element size was defined as the length of the pickup $(447 \mathrm{~mm})$. Some details of the surface mesh refinement of wheels and trunk is given in Fig. 8 .

The main refinement regions and the boundary elements are depicted on Fig. 9, which represents the surface mesh on the symmetry plane.

The mesh used in this work, namely baselinemesh, was around 8 million elements. Previous works also used RANS simulations: Mokhtar et al. (2009) with 700 thousand; Moussa et al. (2015) used 3 million cells for half domain (symmetry); Guilmineau (2010) with 16.6 million; Ha et al. (2011) with 3 million; Holloway et al. (2009) used 26 million and Chen and Khalighi (2015) with 39 million, for the complete vehicle. In comparison to previous work and due to the main focus of describing the mean flow structures, the mesh was considered reasonable, especially for the available computational capacity. The CFD calculations were performed in a workstation with an Intel Core i7$3930 \mathrm{~K}(3.20 \mathrm{GHz})$ processor with twelve cores (six physical) and 48.0 GB RAM memory. For this numerical approach, mean iteration time was 12 seconds when all cores were used. Due to the complexity of the problem and its transient behavior (Holloway et al. (2009)), re lative high order residuals were achieved for all considered quantities, as seen on Fig.10. Also, mesh quality was highly restricted by the elements at the contacts of the wheels with the ground, leading to the existent residuals fluctuations.

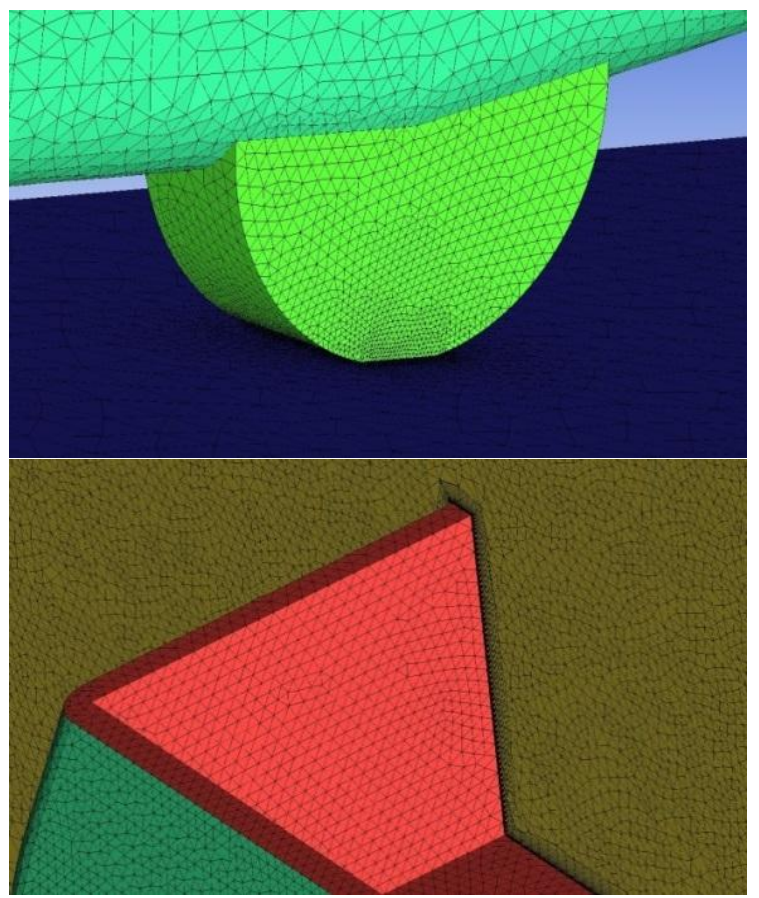

Figure 8. Surface mesh of wheel (top) and trunk (bottom).

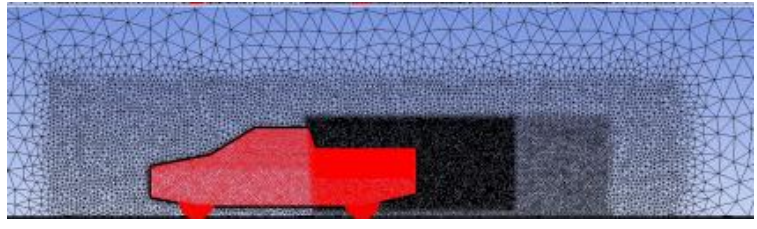

Figure 9. Nu merical surface mesh on symmetry plane pickup - Baseline mesh).

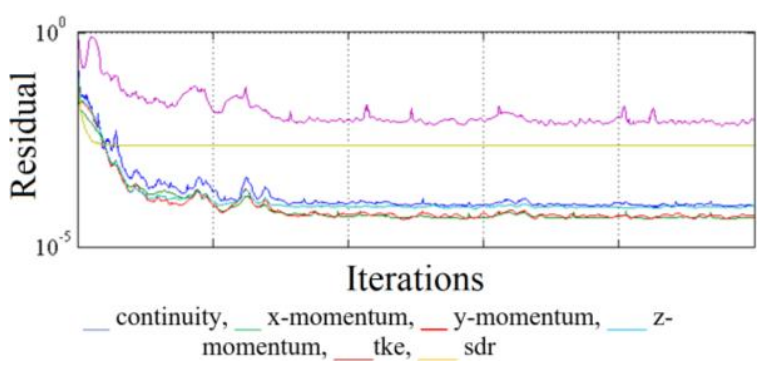

Figure 10. Residuals monitor for simulation with Baseline mesh $\left(\mathrm{U}_{0}=25 \mathrm{~m} / \mathrm{s}\right)$.

\section{RES ULTS AND DISCUSS ION}

Quantitative and qualitative numerical and experimental results are presented in the next subsections showing respectively, u-velocity profiles upstream and downstream the model, spectral analysis of the velocity signals recorded in the pickup's wake and a comparison between wall tufts flow visualization and shear-stress streamlines obtained by CFD, which are illustrated to characterize the flow pattern around the pickup model. At the end part of this section, additional pressure coefficient (cp) calculation over the pickup surface and the aerodynamics force coefficients are given from the CFD calculations at this time of research. Additional wind tunnel test data will be gathered in near future to complement this analysis and will be shown in other publications. All the results allowed a satisfactory characterization of the flow pattern over the pickup truck model showing potential for research and development studies with pickups with relatively low-cost methodologies to analyze such class of problem in aerodynamics of road vehicles.

\section{Quantitative - Velocity Profiles}

Data from the wind tunnel flow quality has been presented by Almeida et al. (2017) and will be not reproduced herein. Flow uniformity was expected upstream the pickup model. The turbulent intensity was around $0.81 \%$ for the range of velocities investigated in this work.

Fig. 11 and Fig. 12 presents the numerical and experimental velocity profiles for the three points investigated (P1) at upstream position and (P2), (P3) at downstream position. In these plots the measured u-velocity (U) was normalized by the maximum 
measured velocity $\left(U_{\max }\right)$ in the vertical line. Fig. 11 describes the u-velocity profile for a flow speed of $16.7 \mathrm{~m} / \mathrm{s}$ and Fig. 12 describes the u-velocity profile for a flow speed of $25 \mathrm{~m} / \mathrm{s}$.
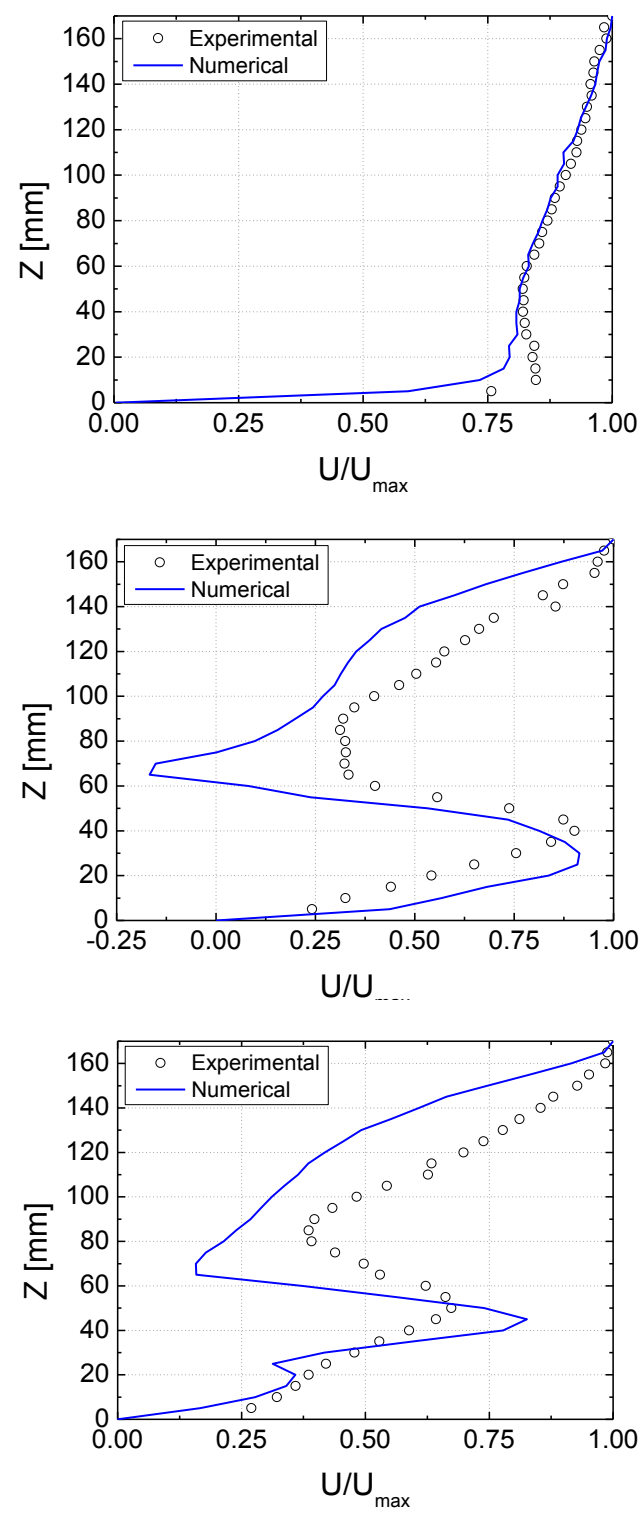

Figure 11. Nu merical and experimental velocity profiles at $\mathrm{U}_{0}=16.7 \mathrm{~m} / \mathrm{s}$.

The comparison with CFD results has indicated the same trend for all plots. On P1 (upstream the model) boundary layer was defined between 0 to $10 \mathrm{~mm}$, deviation outside the boundary layer region was of the order of $1 \%$. For P2, there was an increase of velocity until $40 \mathrm{~mm}$ that can be associated to underbody flow acceleration, followed by a rapid decrease. A region of reverse flow could be identified after the trunk being in the data represented by a plateau of absolute values $6 \mathrm{~m} / \mathrm{s}$ for $\mathrm{U}_{0}=16.7 \mathrm{~m} / \mathrm{s}$ and $9 \mathrm{~m} / \mathrm{s}$ for $\mathrm{U}_{0}=25.0 \mathrm{~m} / \mathrm{s}$ from around 60 to $90 \mathrm{~mm}$ on the rear profiles. The wake continues until the highest point considered $(170 \mathrm{~mm})$. At the last position, the curve was the same that the one observed in the previous acquisition plane, however the structures are dislocated in position and velocity magnitude (higher and slower).

When analyzing the profiles acquired on the wake (P2 and P3), it was noticed that the experimental curves are smother than the numerical ones and the minimum speed was around $5 \mathrm{~m} / \mathrm{s}$, despite the expected negative magnitudes on this region of reverse flow, as indicated by the numerical results. However, due to the limitations of the measuring technique, values outside the calibration regions (including negative velocities) were not correctly acquired and could not indicate the intensity of the reverse flow region. In this case, the minimum velocity for almost all points was fixed around $1 \mathrm{~m} / \mathrm{s}$ (the calibration inferior limit). In this case, the hotwire probe was either inside or crossing the reverse flow zone behind the tailgate, by assuming that in the experiment the location was the same as in CFD data.
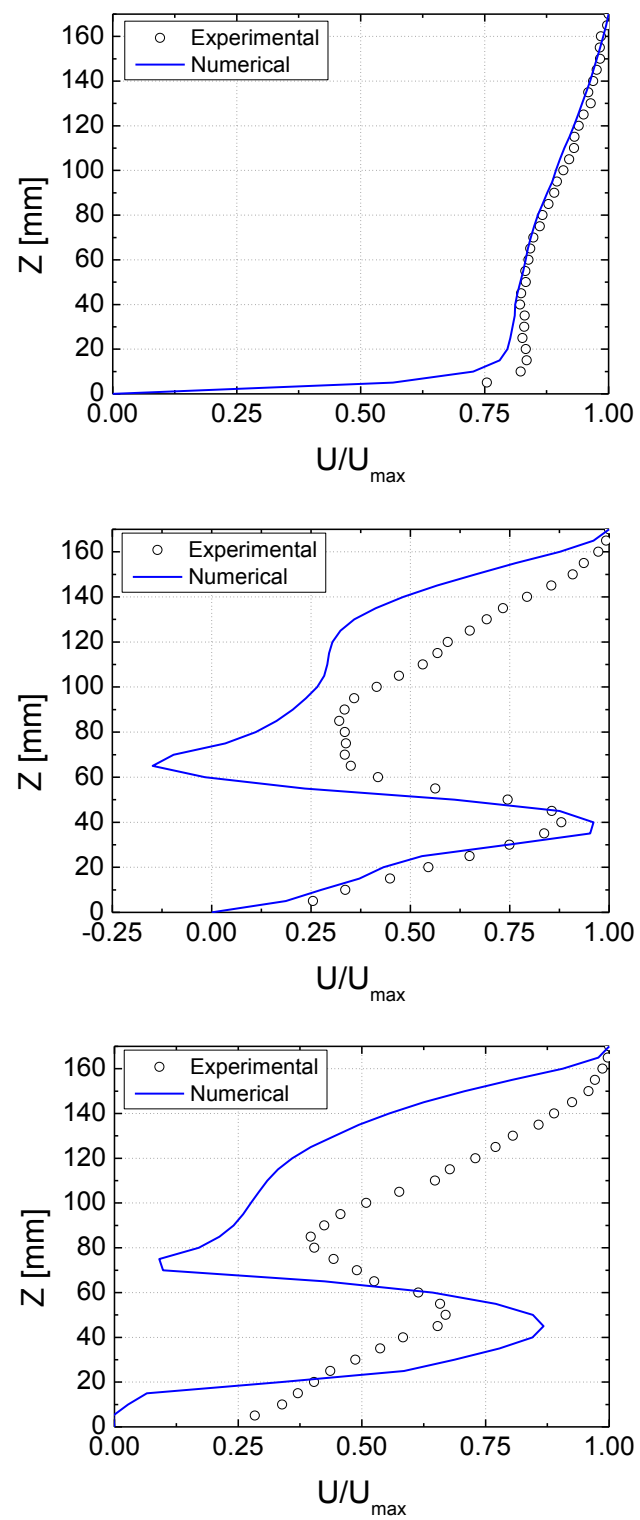

Figure 12. Numerical and experimental velocity profiles at $\mathrm{U}_{0}=25 \mathrm{~m} / \mathrm{s}$. 
Vortex shedding frequency could be obtained using spectral analysis of the velocity signals recorded on the wake. Spectral study of the acquired signals was performed by using MATLAB ${ }^{\circledR}$ Fast Fourier Transform function. Fig. 13 illustrates energy distribution for signal acquired at $\mathrm{Z}=55 \mathrm{~mm}$ on $\mathrm{P} 2$ and P3. For the example, a global peak was noticed around $45 \mathrm{~Hz}$, however, many scales are excited on the wake of the tested geometry, what denotes that the flow is completely developed and turbulent following a $-5 / 3 \mathrm{k}$ rule for turbulent kinetic energy cascade, as depicted in the Fig. 13.

Energy distribution on frequency scale for all tested positions on wake is presented on Fig. 14. Each column of the grid is the spectral distribution of the signal obtained with the probe on the position represented on the abscissa axis for the two positions on symmetry plane (P2 and P3). For clarity, spectra presented on the grid representation are performed for 1024 points; higher discretization was used for vortex shedding frequency determination.
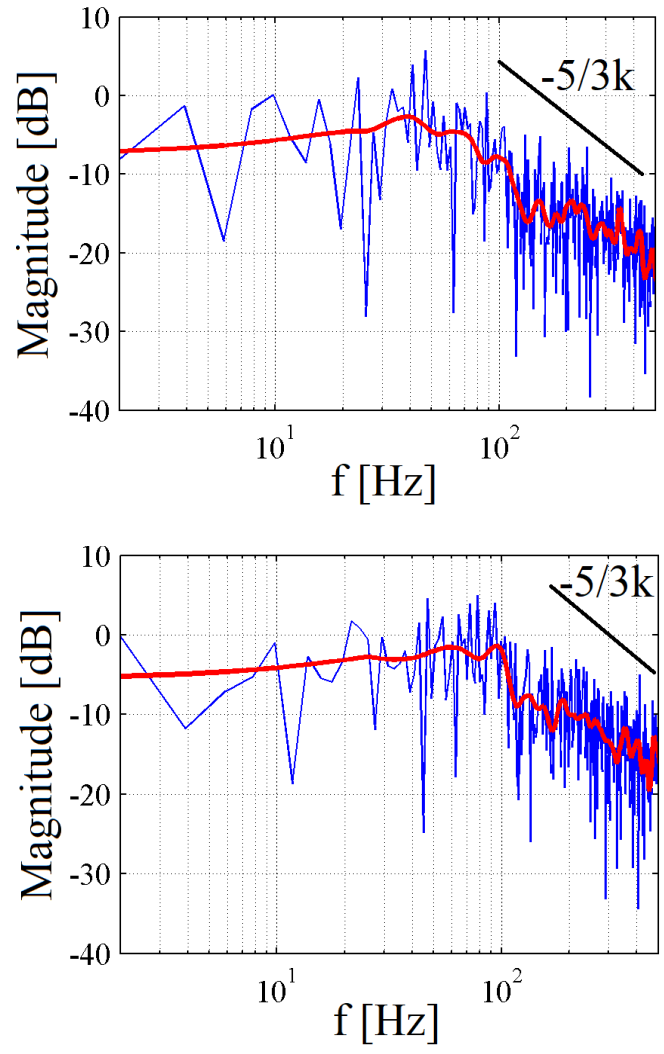

Figure 13. Spectral energy distribution for velocity signal acquired at P2 (top) and P3 (bottom), $\mathrm{Z}=55$ $\mathrm{mm}\left(\mathrm{U}_{0}=25 \mathrm{~m} / \mathrm{s}\right)$, using unity as reference for decibels (smoothed curve in red).

For $\mathrm{U}_{0}=16.7 \mathrm{~m} / \mathrm{s}$, higher magnitudes are seen for a frequency bandwidth of $[40 ; 60] \mathrm{Hz}$, and on the same level of the negative velocities in the numerical profiles $(Z=40-60 \mathrm{~mm})$. The other tested velocity presented more intense values on the vicinity of 60 $\mathrm{Hz}$ for $\mathrm{Z}=60 \mathrm{~mm}$.
Both locations of higher energy can be associated with the shear boundary formed on the rear-overhang of the pickup. Frequencies that corresponded to the global energy peak and the corresponding Strouhal number (the height of the model was used as characteristic dimension) are listed on Table 2 . The mean was 0.378 , for a hot-wire probe placed $15 \mathrm{~mm}$ behind the tailgate, $\mathrm{Ha}$ et al. (2011) observed a peak around $\mathrm{f}=30 \mathrm{~Hz}$, that corresponds to $\mathrm{St}=0.167$. One of the reasons for this discrepancy in the Strouhal number may be associated to the flat surfaces and sharp edges of the pickup, which have been chosen to impose a welldefined detached flow in some parts of the model, including the region behind tailgate.
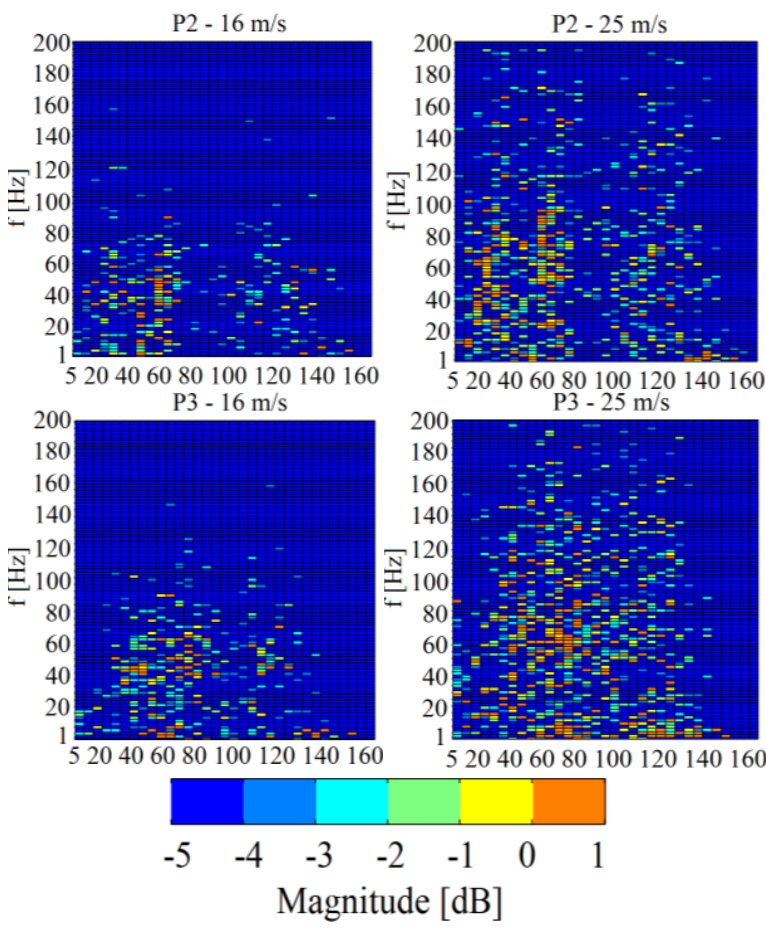

Figure 14. Spectral energy distribution of measured velocities on pickup wake at P2 (top) and P3 (bottom) for $U_{0}=16.7 \mathrm{~m} / \mathrm{s}$ (left colu $\mathrm{mn}$ ) and $\mathrm{U}_{0}=25.0 \mathrm{~m} / \mathrm{s}$ (right column), using unity as reference for decibels.

Table 2. Positions and frequencies of maximu $\mathrm{m}$ spectral energy peaks on pickup wake.

\begin{tabular}{|c|c|c|c|c|}
\hline POSITION & $\mathrm{U}_{0}[\mathrm{~m} / \mathrm{s}]$ & $\begin{array}{c}\mathbf{Z} \\
{[\mathrm{mm}]}\end{array}$ & $\mathbf{F}[\mathbf{H z}]$ & St \\
\hline $\mathrm{P} 2$ & \multirow{2}{*}{16.9} & 55 & 41.634 & 0.370 \\
\hline P3 & & 65 & 43.594 & 0.387 \\
\hline$\overline{\mathrm{P} 2}$ & \multirow{2}{*}{25.0} & 55 & 64.827 & 0.389 \\
\hline P3 & & 65 & 61.012 & 0.366 \\
\hline
\end{tabular}

\section{Qualitative - Flow Visualization}

One of the numerical results is exemplified through the contours of velocity on Fig. 15. The vectors were placed at the experimentally tested locations, providing a general overview about the velocity field around the pickup model. 

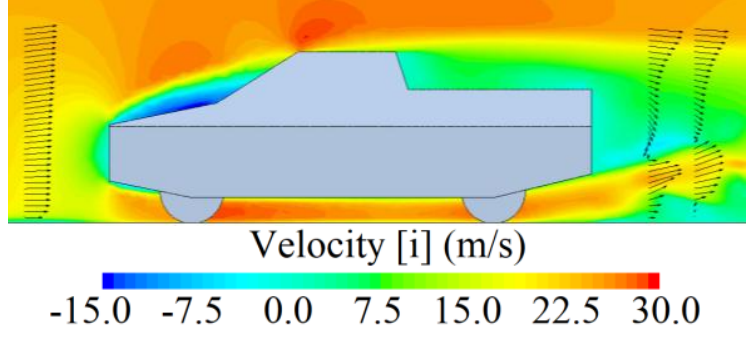

Figure 15 . Streamwise velocity field in symmetry plane and vectors on tested points $\left(U_{0}=25.0 \mathrm{~m} / \mathrm{s}\right)$.

On the first position (P1) it is possible to see the influence of the model on upstream flow. On wake, boundary layer evolution, accelerated flow from underbody and sequential shear boundary are noticed.

For flow pattern visualization, wool tufts were placed on model wall. Wind tunnel testing was performed with two velocities: $U_{0}=\{16.7 ; 25.0\} \mathrm{m} / \mathrm{s}$. Videos and pictures were recorded from lateral of the pickup and above trunk.

Fig. 16, Fig. 17 and Fig. 18 present frames of the recorded videos of the trunk and Fig. 19 illustrates images registered laterally. No clear distinction in terms of flow pattern was observed from one velocity to another, indicating flow similarity inside the trunk and behind the tailgate. Therefore, comparison with numerical results are only made with the fastest velocity $\left(\mathrm{U}_{0}=25 \mathrm{~m} / \mathrm{s}\right)$, which is the one that has more discrepancy among flow zones. From Fig. 16 to Fig. 18 it was observed the presence of a recirculating flow inside the trunk with a small region just behind the cabin where the flow was completely steady with no tufts elevated. A reverse flow was identified in the tailgate region, moving the tufts in the direction of the center of the trunk pointing to the existence of a recirculating bubble.

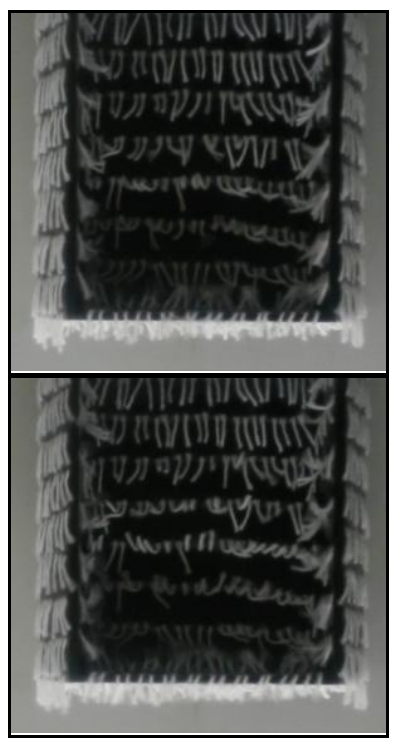

Figure 16. Wall tufts on trunk for $\mathrm{U}_{0}=16.7 \mathrm{~m} / \mathrm{s}$ (top) and $\mathrm{U}_{0}=25.0 \mathrm{~m} / \mathrm{s}$ (bottom).
To compare these results with CFD flow, shear stress streamlines are presented at the surfaces of the model in Fig. 18, showing a top view of the trunk. As identified, tufts on downstream of the trunk were elevated due to the presence of a recirculation zone also predicted on numerical simulations this flow pattern was noted only after the third line of tufts, thus, the recirculation did not take the entire trunk. Also, the reverse flow was completely captured by the CFD simulation, showing the interaction of this flow with the tailgate. Structures that are observed on overall model are illustrated in Fig. 19. Important features are highlighted and labeled sequentially.

As a general description of the flow visualization, flow recirculates above the hood. The limit of the recirculation zone is marked on curve (1) for both results; however, on experiments the recirculation is limited by the hood-front windshield joint. Perturbed tufts at the vicinity of the curve (2) mark the presence of C-pillar vortex. The curve (3) delimitates tufts that are deviated up (above the curve) and down (under the curve). The disturbance of flow downstream the front wheel (4) is also identified. A zone with no adverse flow is delimited above curve (5).

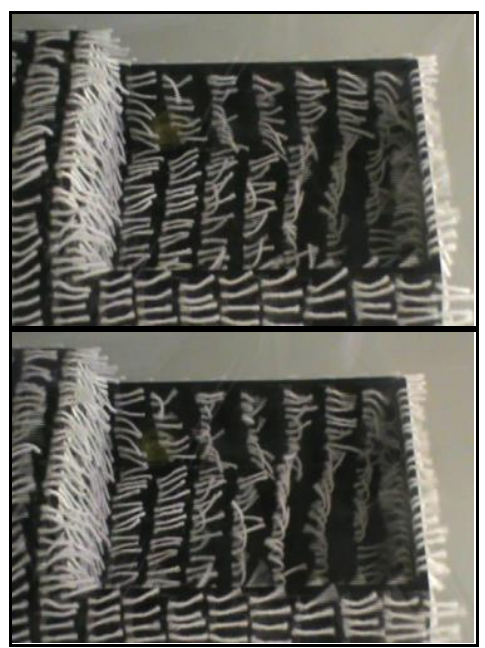

Figure 17. Wall tufts on trunk for $\mathrm{U}^{0}=16.7 \mathrm{~m} / \mathrm{s}$ (top) and $\mathrm{U}^{0}=25.0 \mathrm{~m} / \mathrm{s}$ (bottom).
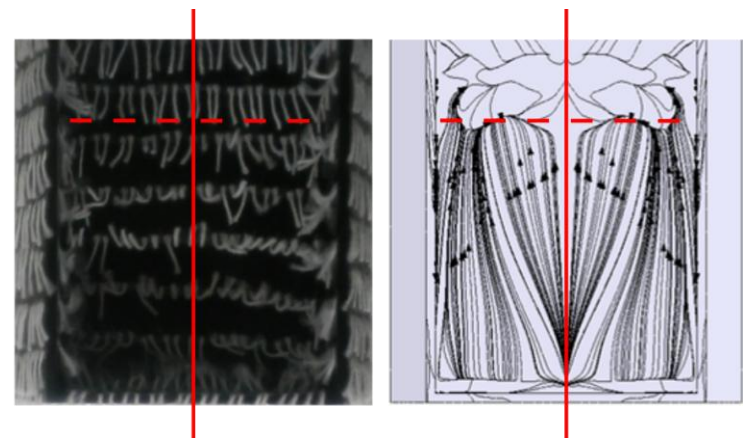

Figure 18. Trunk close wall flow topology for wall tufts test (left) and shear stres s streamlines on trunk surface for BASELINE mesh (right) $\left(\mathrm{U}_{0}=25.0 \mathrm{~m} / \mathrm{s}\right)$. 
Fig. 20 presents the normalized velocity field on the symmetry plane obtained by CFD. Free stream air forms a stagnation zone in front of the pickup model. A detachment zone on the hood front leads to an important recirculation bubble that extends to the front windshield. As noticed on previous works, a recirculation bubble is formed inside the trunk. For the proposed geometry, the bubble does not comprehend the entire trunk, smaller turbulent structures are formed on first $20 \%$ portion of the box, pushing the center of the bubble to the tailgate, as confirmed by the wall tufts.
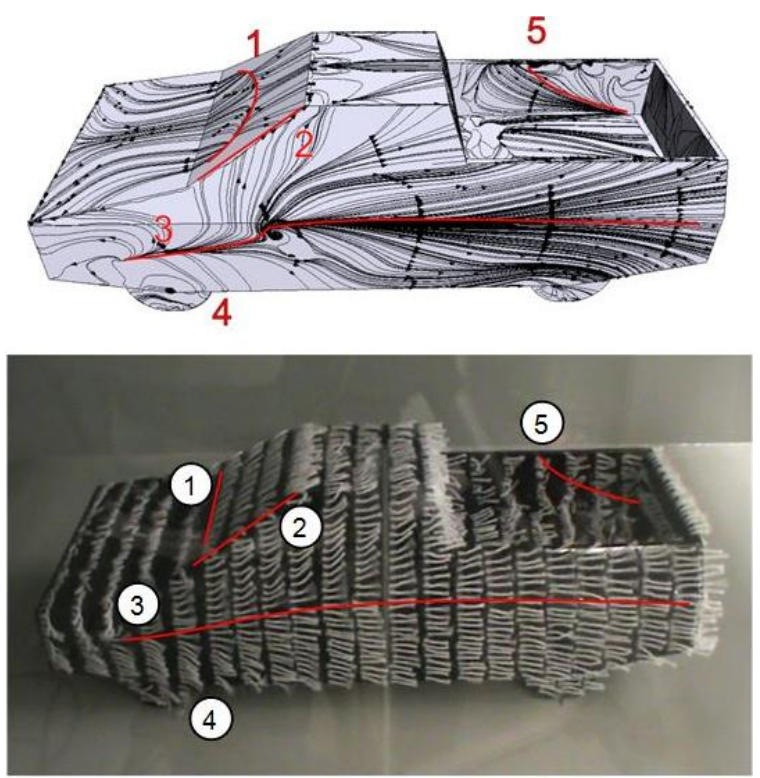

Figure 19. Numerical shear streamlines and wall tufts $\left(\mathrm{U}_{0}=25 \mathrm{~m} / \mathrm{s}\right)$.

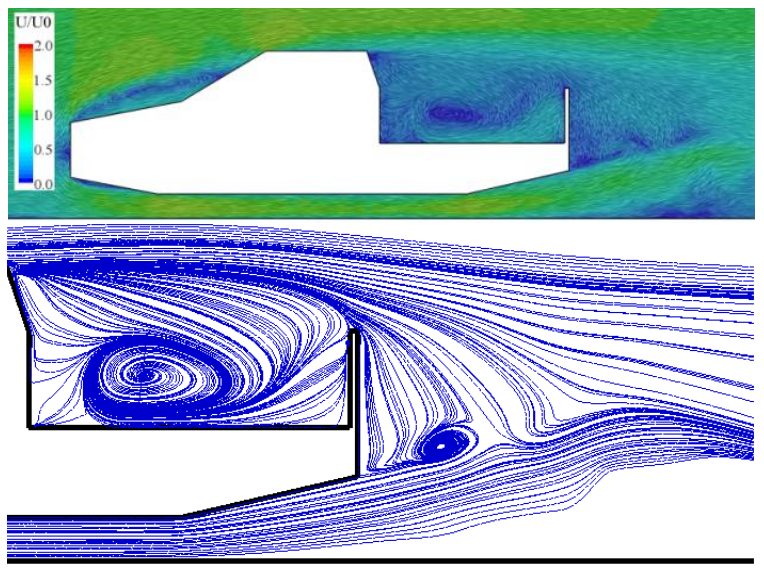

Figure 20. Normalized velocity field (top) and streamlines (bottom) on symmetry plane, baseline model $\mathrm{U}_{0}=25 \mathrm{~m} / \mathrm{s}$.

There were no large recirculation zones outside the tailgate and a shear boundary was formed when the flow was encountered with accelerated air from underbody. A downwash on tailgate external surface was also present, as proposed on the literature. Thus, the flow pattern just behind the tailgate is quite complex, and in this case especially due to the underbody acceleration. Even though no big recirculation zones were identified, it is possible to see the appearance of a small recirculating bubble in the bottom part of the tailgate due to the rendezvous between the upward and downward flow.

To complement the numerical analysis, in the next subsections some quantitative results will be provided in terms of surface pressure coefficient distribution and drag coefficient. These data were obtained only in the CFD calculations at this time. Ongoing experimental tests are scheduled to complement this analysis.

\section{Surface pressure coefficient distribution}

Fig. 21 presents $\mathrm{Cp}$ (surface pressure coefficient) evolution for the cab, bed and underbody obtained from CFD simulations for the velocities $\mathrm{U}_{0}=16.7 \mathrm{~m} / \mathrm{s}$ and $\mathrm{U}_{0}=25 \mathrm{~m} / \mathrm{s}$.
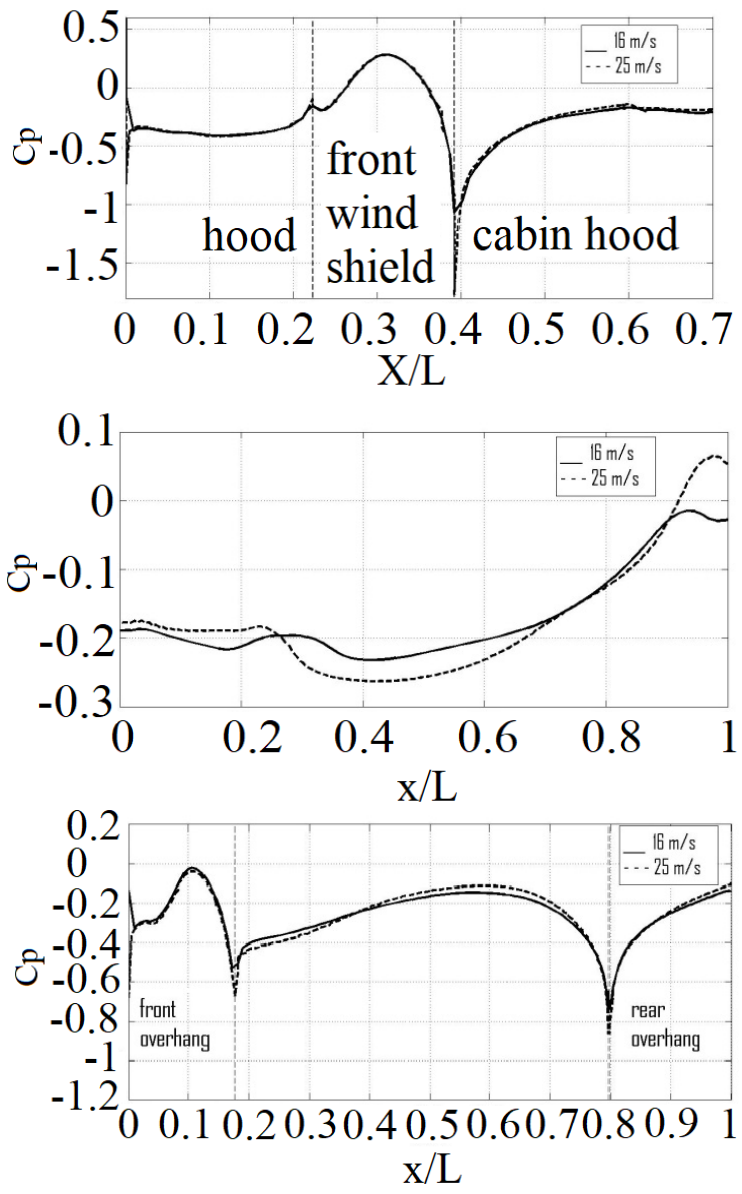

Figure 21. Pressure coefficient on symmetry plane of the cab (top), bed (middle) and underbody (bottom).

For the cab, Cp graphs were very similar and followed the same behavior observed by Al-Garni and Bernal (2010): depression on hood and cabin top and global maximum value on front windshield. 
Comparable trend was noted on bed, where there was a decrease of pressure until about $40 \%$ of the bed followed by an increase up to tailgate. However, the first $20 \%$ of bed presented a plateau of $\mathrm{Cp}=-0.2$ formed by the structures located between the cabin back surface and the recirculation zone. The flow velocity seemed to impose a different pattern in the bed, which was confirmed by the $\mathrm{Cp}$ plots for cabin rear surface and tailgate. On underbody, there was a depression caused by the recirculation of flow on front overhang, only noted on the solution due to the more refined discretization. A stagnation point was formed on the front end and a parabolic $\mathrm{Cp}$ evolution was observed for both solutions, which was not presented on graph.

Differences were more visible on the cabin back surface and the tailgate, see Fig. 22. The recirculating vortex phenomenon on trunk was the cause of the variations observed on bed also producing a higher $\mathrm{Cp}$ on cabin back for $\mathrm{U}_{0}=25 \mathrm{~m} / \mathrm{s}$. On the external face of the tailgate the curves followed the same pattern with only a change in the $\mathrm{Cp}$ values. Outside tailgate, the trend was not completely similar for both flow regimes, with large discrepancy on $\mathrm{Cp}$ values on tailgate root. An important aspect to notice in Fig 21 and Fig 22 is that the curves are smooth, with minimum "wiggles" associated to the mesh discretization and computational solution.
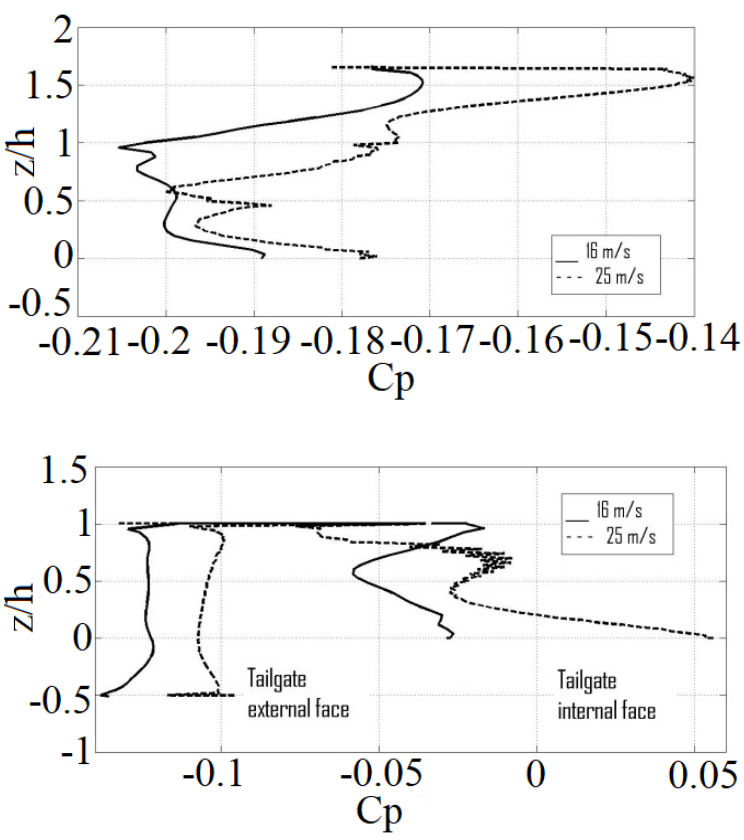

Figure 22. Pressure coefficient on symmetry plane of the cabin rear surface (top) and tailgate (bottom).

\section{Aerodynamic Drag Coefficient}

In terms of drag coefficient (CD), this flat surface and sharp edges pickup model presented a higher $\mathrm{CD}$, when compared with others pickup model presented in literature. Global trend was the same as on previous works on generic pickups (Al-Garni and Bernal (2010); Mokhtar et al. (2009)): for the tested speeds, with the increase of the velocity there was an increase of drag. The drag coefficient varied from $0.5334\left(\mathrm{U}_{0}=16.7 \mathrm{~m} / \mathrm{s}\right)$ to $0.5376\left(\mathrm{U}_{0}=25 \mathrm{~m} / \mathrm{s}\right)$.

In this work, the $C D$ values were obtained only by CFD simulations since there was no experimental measurement of aerodynamics forces in the wind tunnel by the time of this study.

\section{CONCLUS IONS}

A numerical and experimental study of the flow over a commercial vehicle of type pickup was conducted at Reynolds number of order $5 \times 10^{5}$. The pickup model was based on the leaders of light pickup market in Brazil and it was designed only by flat surfaces and sharp edges to enhance the attached/detached/recirculation zones inside the flow field. The results reported in this paper served as basis for a better understanding of the flow pattern around such vehicle and as a baseline for further and enhanced investigations with different vehicle geometry. Velocity profiles measured with hot-wire allowed to identify some aspects of the recirculation zone behind the tailgate, however the size and the strength of this recirculation zone could not be measured with this technique. Wall tufts on surface's model associated with the flow visualization from CFD gave a general overview about the entire flow field around the vehicle and the pressure distribution coefficient obtained only via CFD allowed to identify regions of high and low $\mathrm{CP}$ and its influence on aerodynamics.

For the qualitative and quantitative techniques deployed to describe the flow around the generic pickup model, deviations were noticed from the CFD data. These differences could be either influenced by experimental conditions or limitations imposed by the turbulence modeling. However, we could verify that the global flow pattern was predicted nu merically and that the RANS simulations were considered physically consistent.

As part of an ongoing research, we have identified future work to be done such as refinement of numerical calculation with the test of different turbulence models and the use of unsteady simulation is essential on the continuation of this numerical approach. The use of other experimental procedures such as force coefficients quantification by an aerodynamics balance (which is underway) and oil visualization methods is crucial to validate and extend the results. A study of drag reducing devices and different pickups configurations and geometries is envisaged as next step of this study.

\section{ACKNOWLEDGEMENTS}

The authors would like to thank the support from CPAERO - Experimental Aerodynamics 
Research Center at Federal University of Uberlandia and the partnership with CFD-ADAPCO for providing the software STAR-CCM+.

\section{REFERENCES}

Agelin-Chaab, M., 2014, Structure of Turbulent Flows over Two-Dimensional Bluff Bodies Inspired by a Pickup Truck Geometry, International Journal of Heat and Flu id Flow, Vol. 50, pp. 417-430.

Al-Garni, A. M., 2003, Fundamental Investigation of Road Vehicle Aerodynamics, Doctoral Thesis, Department of Aerospace Engineering, University of Michigan.

Al-Garni, A. M., 2008, Measurements of the Cross-Flow Velocity Field in the Wake of an Idealized Pickup Truck Model Using Particle Image Velocimetry, in: 14th International Symposium On Applications of Laser Techniques to Fluid Mechanics, Lisbon, Portugal.

Al-Garni, A. M., and Bernal, L. P., 2010, Experimental Study of a Pickup Truck Near Wake, Journal of Wind Engineering and Industrial Aerodynamics, Vol. 98, No. 2, pp. 100-112.

Almeida, O., Pinto, W. J. G. S. S., and Rosa, C., 2007, Experimental Analysis of the Flow Over a Commercial Vehicle - Pickup, International Review of Mechanical Engineering, Vol. 11, No. 8, pp. 530537.

Chen, K. -H., and Khalighi, B., 2015, A CFD Study of Drag Reduction Devices for a Full Size Production Pickup Truck, SAE Technical Paper, 011541.

Cooper, K. R., 2004, Pickup Truck Aerodynamics-Keep your Tailgate up, SAE Paper, 2004-01-1146.

Guilmineau, E., 2010, Numerical Simulation of Flow Around a Generic Pickup with ISIS-CFD, Proceedings of ASME 2010 3rd Joint US-European Fluids Engineering Summer Meeting, Montreal, ASME.

Ha, J., Jeong, S., and Obayashi, S., 2011, Drag Reduction of a Pickup Truck by a Rear Downward Flap, International Journal of Automotive Technology, Vol. 12, pp. 369-374.

Ha, J., Obayashi, S., and Kohama, Y., 2009, Drag Characteristics of a Pick Truck According to the Bed Geometry, Proceedings of the 7th IASME/WSEAS International Conference of Fluid Mechanics and Aerodynamics, Vol. 7, pp.122-127.

Holloway, S., Leylek, J. H., and York, W. D., 2009, Aerodynamics of a Pickup Truck: combined CFD and Experimental Study, SAE International Journal of Commercial Vehicles, Vol. 2, No. 1, pp. 88-100.

Hucho, W. H., Janssen, L. J., and Schwarz, G., 1975, The Wind Tunnel's Ground Floor Boundary Layer-Its Interference with the Flow Underneath Cars, SAE Paper 750066.

Menter, F. R., 1994, Two-Equation Eddy-
Viscosity Turbulence Models for Engineering Applications, AIAA Journal, Vol. 32, No. 8, pp. 1598-1605.

Merzkirch, W., 1987, Flow Visualization, 2nd Ed ition, London, Academic Press.

Mokhtar, W. A., Britcher, C. P., and Camp, R. E., 2009, Further Analysis of Pickup Trucks Aerodynamics, SAE Technical Paper 01-1161.

Moussa, A. A., Fischer, J., and Yadav, R., 2015, Aerodynamic Drag Reduction for a Generic Truck Using Geometrically Optimized Rear Cabin Bumps, Journal of Engineering, Artic le ID 789475.

Pinto, W. J. G. S, 2016, Numerical and Experimental Analysis of the Flow over a Commercial Vehicle - Pickup, Undergraduation Conclusion Work in Mechanical Engineering, Federal University of Uberlândia, Uberlândia.

White, F. M., 2003, Fluid Mechanics, 7th Ed ition, Mc Graw-Hill. 